\title{
Sistem Penunjang Keputusan Penentuan Reward Bagi Mitra Terbaik Menggunakan Metode Simple Additive Weighting (SAW) (Studi Kasus : PT. Telkom Akses)
}

\author{
Fandi Aziz ${ }^{1}$, A. Sidiq Purnomo 2 \\ ${ }^{1}$ Informatika, Teknologi Informasi, Universitas Mercu Buana Yogyakarta \\ ${ }^{2}$ Informatika, Teknologi Informasi, Universitas Mercu Buana Yogyakarta \\ 116111060@ student.mercubuana-yogya.ac.id, ${ }^{2}$ sidiq.umby@gmail.com*
}

\begin{abstract}
In the development of the world of work, the reward is a crucial factor in improving the quality of human resources and a form of appreciation for those with improvement. For this reason, companies must be careful in conducting their assessments. Therefore, a decision support system application is needed to assist the company in completing the assessment process. The decision-making process using the Simple Additive Weighting (SAW) method becomes one solution. The results of the system functionality can run well, and as needed, the results of testing the system's accuracy can run well. This shows that the decision support system can function adequately with the Simple Additive Weighting (SAW) method.
\end{abstract}

Keywords: Reward, Simple Additive Weighting (SAW), Decision Support System

\begin{abstract}
Abstrak
Dalam perkembangan dunia kerja , reward merupakan salah satu faktor penting untuk meningkatkan kualitas sumber daya manusia juga sebagai bentuk apresiasi terhadap mereka yang telah mengalami peningkatan. Untuk itu perusahaan harus teliti dalam melakukan penilaiannya. Oleh karena itu dibutuhkan aplikasi sistem penunjang keputusan untuk membantu perusahaan dalam melakukan proses penilaian. Untuk mendukung hal itu proses pengambilan keputusan menggunakan metode Simple Additive Weighting (SAW). Hasil dari fungsionalitas sistem dapat berjalan dengan baik dan sesuai yang dibutuhkan, hasil pengujian akurasi sistem dapat berjalan dengan baik. Hal ini menunjukkan bahwa sistem penunjang keputusan dapat berfungsi dengan baik dengan metode Simple Additive Weighting (SAW).
\end{abstract}

Kata kunci: Reward, Simple Additive Weighting (SAW), Sistem Pendukung Keputusan.

\section{Pendahuluan}

\subsection{Latar Belakang}

PT. Telkom Akses (PTTA) merupakan anak perusahaan PT. Telekomunikasi Indonesia, Tbk yang bergerak yang telah ditetapkan oleh PTTA dimana setiap tahur dibidang penyediaan layanan konstruksi dan akan dievaluasi untuk tetap menjaga kualitas pengelolaan infrastuktur jaringan broadband dimana pembangunan sesuai standar yang diharapkan.

salah satu bentuk komitmen Telkom untuk menghadirkan akses informasi dan komunikasi yang Dengan banyaknya perusahaan kerjasama dibawah terjangkau tanpa batas ke seluruh masyarakat Indonesia naungan PTTA, dan guna untuk menjaga persaingan yang diharapkan dapat membantu meningkatkan yang sehat PTTA memiliki program kerja yaitu kualitas sumber daya manusia agar mampu bersaing di pemberian reward bagi mitra terbaik, namun selama ini level dunia. Berdasarkan komitmen tersebut PTTA akan terus keabsahannya. Untuk memcahkan masalah tersebut mengembangkan layanannya hingga mencakup seluruh diperlukan sebuah sistem penunjang keputusan wilayah Indonesia yang saat ini telah mencapai 30 node pemberian reward dengan berbagai macam aspek terra route dan sekitar 8.500 lebih kilometer kabel serat penilaian yang dinilai cukup penting untuk dijadikan optic. Tidak hanya terus meningkatkan layanan dibidang bahan acuan penilaian.

infrastruktur saja , melalui Visi Misi perusahaan PTTA juga akan terus mengembangkan sumber daya manusia 1.2. Tinjauan Pustaka

nya agar dapat menciptakan sebuah hasil karya yang memiliki standar sehingga memberikan dampak positif Pada penelitian yang dilakukan di Amri Supermarket bagi perusahaan agar tetap bisa bersaing untuk menjadi yang terbaik
Untuk mempercepat pengembangan infrastuktur jaringan broadband PTTA bekerja sama dengan mitra dan saat ini ada kurang lebih 14 perusahaann yang bergabung dengan PTTA dengan sistem kontrak kerja penilaian cenderung hanya berdasarkan pendapat pribadi manajer sehingga penilaian kurang diyakini 1.2. Tinjauan Pustaka

Pada penelitian yang dilakukan di Amri Supermarket
Banjar Jaya untuk memilih karyawan terbaik menggunakan metode Simple Additive Weighting (SAW). Dalam penilitian ini membahas penilaian karyawan yang berdasarkan 5 kriteria yang telah dipilih 
yaitu kinerja, presensi, perilaku, penampilan dan atribut. pada tahap perencanaan agar ditentukan / dengan Penilaian yang dilakukan berdasarkan data karyawan memperhatikan kriteria - kriteria berdasarkan tujuan dari setiap divisi yang sebelumnya telah dinilai setiap yang akan dicapai.

bulannya sehingga menghasilkan output 3 nama

karyawan yang memiliki nilai paling tinggi dari yang 4.Tahap Impelementasi (Implementation Phace).

berasal dari divisi yang berbeda [7].

Tahap ini dilakukan penerapan terhadap rancangan Penelitian mengenai pemberian reward yang sistem yang telah dibuat pada tahap perancanagan serta berdasarkan penilaian kinerja karyawan menggunakan pelaksanaan alternatif tindakan yang telah dipilih pada metode AHP. Penelitian yang dilakukan di PT. Anugrah tahap pemilihan.

Protecindo menetapkan 4 bobot kriteria yaitu motivasi,

kompetensi, keterampilan, dan sikap. Prosentase Metode Simple Additive Weighting (SAW) dikenal kenaikan penilaian kinerja dari standar yang ditetapkan dengan istilah metode penjumlahan terbobot. Konsep akan dibandingkan dengan total prosentase kenaikan dasar pada metode SAW adalah mencari penjumlahan penilaian kinerja dari seluruh karyawan, sehingga terbobot dari rating kinerja pada setiap alternatif di didapatkan sebuah nilai akhir yang akan dikalikan semua atribut. Metode SAW membutuhkan proses dengan dana yang dialokasikan untuk reward [2].

Penelitian untuk memilih lokasi cabang baru Toko yang Pakan UD. Indo Multi Fish menggunakan metode menggunakan Persamaan 1.

Simple Additive Weighting (SAW). Memanfaatkan kriteria-kriteria yang dapat meningkatkan laba perusahaan dengan mengkombinasikan 5 alternatif pilihan tempat yang dipadukan dengan 6 kriteria sehingga mendapatkan hasil satu tempat dimana memiliki penilaian paling tinggi dari alternatif pilihan yang lain [6].

\subsection{Landasan Teori}

Sistem Pendukung Keputusan (SPK) atau Decision Support System (DSS) merupakan sistem informasi interaktif yang menyediakan informasi, pemodelan dan pemanipulasian data. Sistem ini digunakan untuk membantu pengambil keputusan dalam situasi yang semi terstruktur dan situasi yang tidak terstruktur dimana tidak seorangpun tahu secara pasti bagaimana keputusan seharusnya dibuat [4]. Tahapan SPK memiliki beberapa tahapan antara lain :

1.Tahap Pemahaman (Inteligence Phace).

$r_{j j}\left\{\begin{array}{l}\frac{\mathrm{X}_{\mathrm{ij}}}{\operatorname{Max}_{\mathrm{i}} \mathrm{X}_{\mathrm{ij}}} \rightarrow \begin{array}{l}\text { jika } \mathrm{j} \text { adalah attribute keuntungan } \\ \text { (benefit) }\end{array} \\ \frac{\mathrm{Min}_{\mathrm{i} j}}{\mathrm{X}_{\mathrm{ij}}} \rightarrow \begin{array}{l}\text { jika } \mathrm{j} \text { adalah attribute biaya } \\ (\text { cost })\end{array}\end{array}\right.$

Keterangan :

$\mathrm{Rjj}=$ Nilai rating kinerja ternormalisasi

$\mathrm{Xij}=$ Nilai atribut yang dimiliki dari setiap kriteria

Max $\mathrm{Xjj}_{\mathrm{jj}}=$ Nilai terbesar dari setiap kriteria

Min Xjj = Nilai terkecil dari setiap kriteria

Benefit $=$ Jika nilai terbesar adalah yang terbaik

Cost $=$ Jika nilai terkecil adalah yang terbaik

Selanjutnya nilai preferensi yang diberikan untuk setiap Tahap ini merupakan proses penelusuran dan alternatif maka bisa menggunakan Persamaan 2. pendeteksian dari lingkup problematika serta proses pengenalan masalah. Data masukan diperoleh, diproses $V_{i}=\sum_{j=1}^{n} w_{j}$ dan diuji dalam rangka mengidentifikasikan masalah.

\section{Tahap Perancangan (Design Phace).}

\section{Keterangan :}

Vi $=$ Nilai preferensi

Tahap ini merupakan proses pengembangan dan pencarian alternatif tindakan / solusi yang dapat diambil. Tersebut merupakan representasi kejadian nyata yang disederhanakan, sehingga diperlukan proses validasi dan vertifikasi untuk mengetahui keakuratan model dalam meneliti masalah yang ada.

$w j=$ Bobot rangking

rij = Rating kinerja ternormalisasi

\section{Metode Penelitian}

3.Tahap Pemilihan (Choice Phace).

\subsection{Data Penelitian}

Data yang digunakan untuk proses penelitian ini adalah Tahap ini dilakukan pemilihan terhadap data mitra PT. Telkom Akses Yogyakarta diantaraberbagai alternatif solusi yang dimunculkan 


\subsection{Tahap Penelitian}

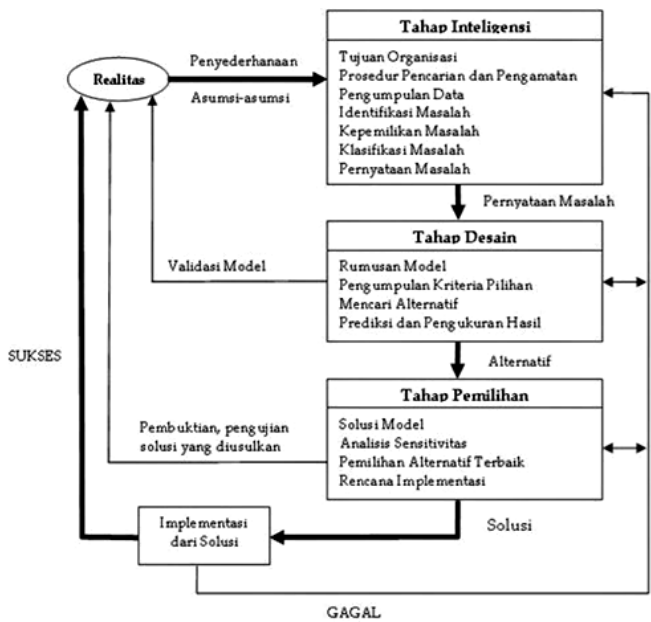

Gambar 1. Tahapan Penelitian

Pada tahapan ini merupakan langkah - langkah yang dilakukan untuk mendapatkan data yang dibutuhkan sebagai penunjang penelitian, yaitu dengan membaca buku - buku,artikel yang membahas tentang metode Simple Additive Weighting (SAW) dan sistem penunjang keputusan,serta mencari informasi dengan wawancara. Dalam perhitungan manual menggunakan metode Simple Additive Weightiing (SAW)

1. Menentukan kriteria yang dalam kasus pemberian reward ini terdapat empat (4) seperti yang ditunjukkan pada Tabel 1.

\begin{tabular}{llll}
\multicolumn{3}{c}{ Tabel 1. Kriteria } \\
\hline No & Kriteria & Bobot & Keterangan \\
\hline $\mathbf{1}$ & Rekonsiliasi Data & 40 & Max \\
\hline $\mathbf{2}$ & Atribut & 20 & Max \\
\hline $\mathbf{3}$ & Absensi & 10 & Max \\
\hline $\mathbf{4}$ & Kinerja & 30 & Max \\
\hline
\end{tabular}

2. Memberikan rating nilai kecocokan seperti yang ditunjukan pada Tabel 2 .

Tabel 2. Rating Nilai Kecocokan

\begin{tabular}{lll} 
No & Rating Nilai & $\begin{array}{l}\text { Tabel } \\
\text { Keterangan }\end{array}$ \\
\hline $\mathbf{1}$ & $81-100$ & Sangat Baik (SB) \\
\hline $\mathbf{2}$ & $61-80$ & Baik (B) \\
\hline $\mathbf{3}$ & $41-60$ & Cukup (C) \\
\hline $\mathbf{4}$ & $21-40$ & Kurang (K) \\
\hline $\mathbf{5}$ & $1-20$ & Sangat Kurang (SK)
\end{tabular}

3. Rating Nilai Kecocokan setiap Alternatif pada setiap Kriteria.

Pemberian nilai rating ini bertujuan sebagai nilai awal dari metode SAW,seperti dapat dilihat pada Tabel 3.
Tabel 3. Rating Nilai Kecocokan Setiap Alternatif pada Setiap Kriteria

\begin{tabular}{|c|c|c|c|c|c|}
\hline \multirow{3}{*}{ No } & \multirow{3}{*}{$\begin{array}{c}\text { Alternati } \\
\text { f }\end{array}$} & \multicolumn{4}{|c|}{ Kriteria } \\
\hline & & Rekonsil & Atribu & Absens & Kinerj \\
\hline & & iasi Data & $\mathbf{t}$ & $\mathbf{i}$ & $\mathbf{a}$ \\
\hline 1 & $\begin{array}{l}\text { PT. GRI } \\
\end{array}$ & 95 & 95 & 95 & 85 \\
\hline 2 & PT.SSK & 90 & 75 & 85 & 85 \\
\hline 3 & PT. GMJ & 65 & 55 & 75 & 75 \\
\hline 4 & PT. TTU & 70 & 80 & 75 & 75 \\
\hline 5 & PT. JS & 75 & 85 & 85 & 90 \\
\hline 6 & PT. ZAG & 79 & 65 & 70 & 85 \\
\hline 7 & $\begin{array}{l}\text { PT. } \\
\text { FMKA }\end{array}$ & 79 & 65 & 40 & 55 \\
\hline 8 & PT. PPR & 40 & 45 & 50 & 60 \\
\hline 9 & PT. SIPP & 55 & 35 & 45 & 65 \\
\hline 10 & $\begin{array}{l}\text { PT. GTI } \\
\end{array}$ & 45 & 35 & 45 & 45 \\
\hline 11 & PT. SJU & 20 & 10 & 25 & 15 \\
\hline 12 & $\begin{array}{l}\text { PT. } \\
\text { PJMA }\end{array}$ & 55 & 25 & 30 & 30 \\
\hline 13 & PT. KES & 55 & 20 & 25 & 30 \\
\hline 14 & $\begin{array}{l}\text { PT. } \\
\text { MGM }\end{array}$ & 20 & 20 & 10 & 15 \\
\hline
\end{tabular}

\section{Matriks keputusan dan Normalisasi}

Langkah selanjutnya adalah mengubah nilai alternatif disetiap kriteria ke dalam bentuk matriks seperti yang ditunjukkan pada Persamaan 3.

$$
R=\left[\begin{array}{cccc}
1 & 1 & 1 & 0,944 \\
0,947 & 0,789 & 0,894 & 0,944 \\
0,684 & 0,578 & 0,789 & 0,833 \\
0,736 & 0,842 & 0,631 & 0,722 \\
0,789 & 0,894 & 0,894 & 1 \\
0,831 & 0,684 & 0,736 & 0,944 \\
0,831 & 0,684 & 0,421 & 0,611 \\
0,421 & 0,473 & 0,526 & 0,666 \\
0,578 & 0,368 & 0,473 & 0,722 \\
0,473 & 0,368 & 0,473 & 0,5 \\
0,210 & 0,105 & 0,263 & 0,166 \\
0,578 & 0,263 & 0,315 & 0,333 \\
0,578 & 0,210 & 0,263 & 0,333 \\
0,210 & 0,210 & 0,105 & 0,166
\end{array}\right]
$$

Matriks diatas diperoleh dengan menggunakan rumus dari Persamaan 1 sebagai berikut contoh perhitungan untuk $\mathrm{R}_{11}, \mathrm{R}_{21}, \mathrm{R}_{31}, \mathrm{R}_{41}$ dibawah ini

$$
R_{11}=\frac{95}{\max \{95 ; 90 ; 65 ; 70 ; 75 ; 79 ; 79 ; 40 ; 55 ; 45 ; 20 ; 55 ; 55 ; 20\}}=\frac{95}{95}=1
$$

$R_{21}=\frac{95}{\max \{95 ; 75 ; 55 ; 80 ; 85 ; 65 ; 65 ; 45 ; 35 ; 35 ; 10 ; 25 ; 25 ; 20\}}=\frac{95}{95}=1$

$R_{31}=\frac{95}{\max \{95 ; 85 ; 75 ; 60 ; 85 ; 70 ; 40 ; 50 ; 45 ; 45 ; 25 ; 30 ; 25 ; 10\}}=\frac{95}{95}=1$

$$
R_{41}=\frac{85}{\max \{85 ; 85 ; 75 ; 65 ; 90 ; 85 ; 55 ; 60 ; 65 ; 45 ; 15 ; 30 ; 30 ; 15\}}=\frac{85}{90}
$$


5. Perangkingan yang diperoleh dari perkalian ternormalisasi dengan vektor bobot.

Apabila dijabarkan perhitungannya maka sebagai berikut :

$$
\begin{gathered}
V_{1}=(1 * 4)+(1 * 2)+(1 * 1)+(0,94 * 3)=9,8 \\
V_{2}=(0,95 * 4)+(0,79 * 2)+(0,89 * 1) \\
+(0,94 * 3)=9,09 \\
V_{3}=(0,68 * 4)+(0,58 * 2)+(0,79 * 1) \\
+(0,83 * 3)=7,16
\end{gathered}
$$

Demikian seterusnya $\mathrm{V}_{4}, \mathrm{~V}_{5} \ldots \ldots . \quad \mathrm{V}_{\mathrm{n}}$, sehingga menghasilkan nilai keseluruhan dari setiap alternatif yang ditunjukan pada Tabel 4 .

Tabel 4. Hasil Akhir Perkalian

\begin{tabular}{ccccccc}
\hline \multirow{2}{*}{ No } & Alternatif & \multicolumn{5}{c}{ Bobot Kriteria (C) } \\
\cline { 3 - 6 } & $(\mathbf{A})$ & $\mathbf{4 0}$ & $\mathbf{2 0}$ & $\mathbf{1 0}$ & $\mathbf{3 0}$ & \\
\hline $\mathbf{1}$ & PT. GRI & 40 & 20 & 10 & 28,32 & 98,32 \\
\hline $\mathbf{2}$ & PT.SSK & 37,88 & 15,78 & 8,94 & 28,32 & 90,92 \\
\hline $\mathbf{3}$ & PT. GMJ & 27,36 & 11,56 & 7,89 & 24,99 & 71,8 \\
\hline $\mathbf{4}$ & PT. TTU & 29,44 & 16,84 & 6,31 & 21,66 & 74,25 \\
\hline $\mathbf{5}$ & PT. JS & 31,56 & 17,88 & 8,94 & 30 & 88,38 \\
\hline $\mathbf{6}$ & PT. ZAG & 33,24 & 13,68 & 7,36 & 28,32 & 82,6 \\
\hline $\mathbf{7}$ & PT. FMKA & 33,24 & 13,68 & 4,21 & 18,33 & 69,46 \\
\hline $\mathbf{8}$ & PT. PPR & 16,84 & 9,46 & 5,26 & 19,98 & 51,54 \\
\hline $\mathbf{9}$ & PT. SIPP & 23,12 & 7,36 & 4,73 & 21,66 & 56,87 \\
\hline $\mathbf{1 0}$ & PT. GTI & 18,92 & 7,36 & 4,73 & 15 & 46,01 \\
\hline $\mathbf{1 1}$ & PT. SJU & 8,4 & 2,1 & 2,63 & 4,98 & 18,11 \\
\hline $\mathbf{1 2}$ & PT. PJMA & 23,12 & 5,26 & 3,15 & 9,99 & 41,52 \\
\hline $\mathbf{1 3}$ & PT. KES & 23,12 & 4,2 & 2,63 & 9,99 & 39,94 \\
\hline $\mathbf{1 4}$ & PT. MGM & 8,4 & 4,2 & 1,05 & 4,98 & 18,63 \\
\hline & & & & & &
\end{tabular}

6. Hasil perangkingan

Nilai yang didapatkan dari masing-masing V yaitu V1 =

$9,8, \mathrm{~V} 2=9,09, \mathrm{~V} 3=7,6$, seterusnya unutk V4, Secara umum alur sistem yang dibuaat dapat dilihat pada

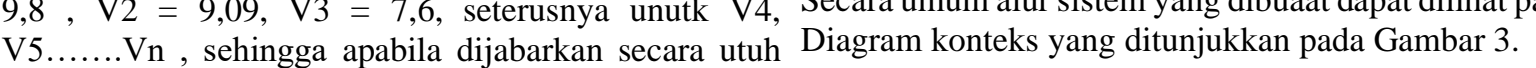
maka hasil penilaian untuk setiap alternatif dapat dilihat melalui Tabel 5.

\begin{tabular}{clcc}
\multicolumn{4}{c}{ Tabel 5. Hasil Perangkingan } \\
\hline No & Alternatif & $\begin{array}{c}\text { Hasil } \\
\text { Akhir }\end{array}$ & Rangking \\
\hline $\mathbf{1}$ & PT. GRI & 98,32 & 1 \\
\hline $\mathbf{2}$ & PT.SSK & 90,92 & 2 \\
\hline $\mathbf{3}$ & PT. JS & 88,38 & 3 \\
\hline $\mathbf{4}$ & PT. ZAG & 82,6 & 4 \\
\hline $\mathbf{5}$ & PT. TTU & 74,25 & 5 \\
\hline $\mathbf{6}$ & PT. GMJ & 71,8 & 6 \\
\hline $\mathbf{7}$ & PT. FMKA & 69,46 & 7 \\
\hline $\mathbf{8}$ & PT. SIPP & 56,87 & 8 \\
\hline
\end{tabular}

\begin{tabular}{clcc}
\hline $\mathbf{9}$ & PT. PPR & 51,54 & 9 \\
\hline $\mathbf{1 0}$ & PT. GTI & 46,01 & 10 \\
\hline $\mathbf{1 1}$ & PT. PJMA & 41,52 & 11 \\
\hline $\mathbf{1 2}$ & PT. KES & 39,94 & 12 \\
\hline $\mathbf{1 3}$ & PT. MGM & 18,63 & 13 \\
\hline $\mathbf{1 4}$ & PT. SJU & 18,11 & 14 \\
\hline
\end{tabular}

\subsection{Analisis Sistem}

Dilakukan analisa data dan permasalahan yang telah dirumuskan, lalu merancang sebuah sistem untuk mengatasi masalah tersebut dan kebutuhan apa saja yang dibutuhkan.

a. Algoritma Sistem



Gambar 2. Algoritma Sistem

b. Diagram konteks



Gambar 3. Diagram Konteks 
c. Rancangan ERD

Rancangan ERD yang digunakan dalam penelitian ini untuk menunjang kebutuhan dalam penyusunan database ditunjukkan pada Gambar 4.

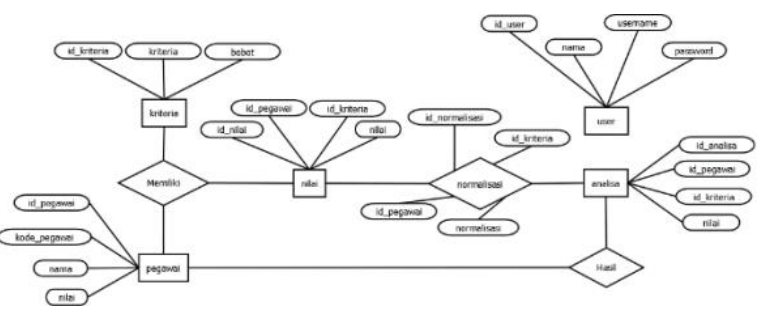

Gambar 4. ER Diagram

\subsection{Implementasi dan Pengujian}

Merupakan tahap akhir dimana sistem siap untuk dioperasikan dan diuji sehingga diketahui apakah sistem yang dibuat sudah benar - benar dapat digunakan sesuai dengan tujuan. Dalam implementasi dan pengujian ini akan digunakan :

a. Perangkat lunak dan perangkat keras.

Dalam pengujian sistem menggunakan perangkat lunak XAMPP sebagai server MySQL database dan penerjemah bahasa pemrograman PHP agar dapat dibuka melalui web browser dengan alamat localhost yang sudah dibuat untuk menampilkan program yang dibuat. Untuk perangkat keras mengunakan laptop dengan spesifikasi Intel Core i5,sistem operasi Windows 10 Pro yang dilengkapi dengan RAM 6 GB serta HDD berkapasitas $500 \mathrm{~GB}$.

\section{b. Coding program PHP.}

Dalam hal ini menggunkan software Atom untuk mengimplemntasikan perhitungan manual yang diubah ke dalam bahasa pemrograman PHP.

\section{Hasil dan Pembahasan}

Hasil dari penelitian dengan membandingkan perhitungan perangkingan metode manual dengan perangkingan dengan sistem dapat dilihat pada Tabel 6 .

\begin{tabular}{|c|c|c|c|c|c|c|c|c|c|c|c|}
\hline \multirow{2}{*}{$\begin{array}{l}\mathrm{N} \\
\mathrm{O}\end{array}$} & \multirow{2}{*}{$\begin{array}{l}\text { ALTER } \\
\text { NATIF }\end{array}$} & \multicolumn{4}{|c|}{ PERHITUNGAN MANUAL } & \multicolumn{4}{|c|}{ PERHITUNGAN SISTEM } & \multirow{2}{*}{$\begin{array}{c}\text { HASI } \\
L \\
\text { MAN } \\
\text { UAL }\end{array}$} & \multirow{2}{*}{$\begin{array}{c}\text { HAS } \\
\text { IL } \\
\text { SIST } \\
\text { EM }\end{array}$} \\
\hline & & C1 & $\mathrm{C} 2$ & C3 & C4 & C1 & $\mathrm{C} 2$ & C3 & $\mathrm{C4}$ & & \\
\hline 1 & PT. GRI & 40 & 20 & 10 & $\begin{array}{l}28, \\
32\end{array}$ & 40 & 20 & 10 & $\begin{array}{l}28 \\
, 2\end{array}$ & $\begin{array}{c}98,3 \\
2\end{array}$ & 98,2 \\
\hline 2 & PT.SSK & 37,88 & $\begin{array}{l}15, \\
78\end{array}$ & $\begin{array}{l}8, \\
94\end{array}$ & $\begin{array}{l}28, \\
32\end{array}$ & 38 & $\begin{array}{l}15 \\
, 8\end{array}$ & $\begin{array}{l}8, \\
9\end{array}$ & $\begin{array}{l}28 \\
, 2\end{array}$ & $\begin{array}{c}90,9 \\
2\end{array}$ & 90,9 \\
\hline 3 & $\begin{array}{l}\text { PT. } \\
\text { GMJ }\end{array}$ & 27,36 & $\begin{array}{l}11, \\
56\end{array}$ & $\begin{array}{l}7, \\
89\end{array}$ & $\begin{array}{l}24, \\
99\end{array}$ & $\begin{array}{l}27 \\
, 2\end{array}$ & $\begin{array}{l}11 \\
, 6\end{array}$ & $\begin{array}{l}7, \\
9\end{array}$ & $\begin{array}{l}24 \\
, 9\end{array}$ & 71,8 & 71,6 \\
\hline 4 & $\begin{array}{l}\text { PT. } \\
\text { TTU }\end{array}$ & 29,44 & $\begin{array}{l}16, \\
84\end{array}$ & $\begin{array}{l}6, \\
31\end{array}$ & $\begin{array}{l}21, \\
66\end{array}$ & $\begin{array}{l}29 \\
, 6\end{array}$ & $\begin{array}{l}16 \\
, 8\end{array}$ & $\begin{array}{l}6, \\
3\end{array}$ & $\begin{array}{l}21 \\
, 6\end{array}$ & $\begin{array}{c}74,2 \\
5\end{array}$ & 74,3 \\
\hline
\end{tabular}

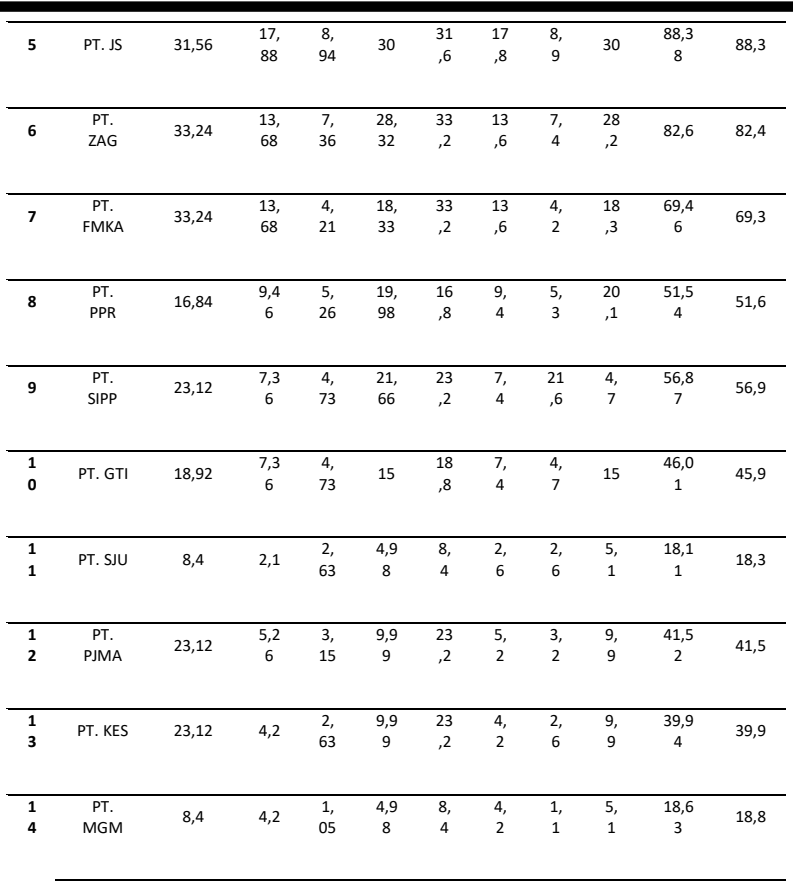

Sehingga bila divalidasi untuk perangkingan baik menggunakan manual maupun sistem hasilnya akan sesuai seperti yang ditampilkan pada Tabel 7.

\begin{tabular}{|c|c|c|c|c|c|c|}
\hline $\begin{array}{l}\mathrm{N} \\
\mathrm{o}\end{array}$ & $\begin{array}{c}\text { Altern } \\
\text { atif }\end{array}$ & $\begin{array}{c}\text { Nilai Akhir } \\
\text { Perhitunga } \\
\text { n Manual }\end{array}$ & Peringkat & $\begin{array}{c}\text { Nilai Akhir } \\
\text { Perhitunga } \\
\text { n Sistem }\end{array}$ & $\underset{t}{\text { Peringka }}$ & $\begin{array}{c}\text { Validasi } \\
\text { (Sesuai/Tidak } \\
\text { ) }\end{array}$ \\
\hline 1 & $\begin{array}{l}\text { PT. GRI } \\
\end{array}$ & 98,32 & 1 & 98,2 & 1 & Sesuai \\
\hline 2 & PT.SSK & 90,92 & 2 & 90,9 & 2 & Sesuai \\
\hline 3 & $\begin{array}{l}\text { PT. } \\
\text { GMJ }\end{array}$ & 71,8 & 6 & 71,6 & 6 & Sesuai \\
\hline 4 & $\begin{array}{l}\text { PT. } \\
\text { TTU }\end{array}$ & 74,25 & 5 & 74,3 & 5 & Sesuai \\
\hline 5 & PT. JS & 88,38 & 3 & 88,3 & 3 & Sesuai \\
\hline 6 & $\begin{array}{l}\text { PT. } \\
\text { ZAG }\end{array}$ & 82,6 & 4 & 82,4 & 4 & Sesuai \\
\hline 7 & $\begin{array}{c}\text { PT. } \\
\text { FMKA }\end{array}$ & 69,46 & 7 & 69,3 & 7 & Sesuai \\
\hline 8 & $\begin{array}{l}\text { PT. } \\
\text { PPR }\end{array}$ & 51,54 & 9 & 51,6 & 9 & Sesuai \\
\hline 9 & $\begin{array}{l}\text { PT. } \\
\text { SIPP }\end{array}$ & 56,87 & 8 & 56,9 & 8 & Sesuai \\
\hline 10 & PT. GTI & 46,01 & 10 & 45,9 & 10 & Sesuai \\
\hline 11 & PT. SJU & 18,11 & 14 & 18,3 & 14 & Sesuai \\
\hline 12 & $\begin{array}{c}\text { PT. } \\
\text { PJMA }\end{array}$ & 41,52 & 11 & 41,5 & 11 & Sesuai \\
\hline 13 & PT. KES & 39,94 & 12 & 39,9 & 12 & Sesuai \\
\hline 14 & $\begin{array}{c}\text { PT. } \\
\text { MGM }\end{array}$ & 18,63 & 13 & 18,8 & 13 & Sesuai \\
\hline
\end{tabular}




\section{Kesimpulan}

Berdasarkan hasil penelitian yang telah dilakukan maka dapat disimpulkan dalam pelakasanaan penilaian mitra terbaik PT. Telkom Akses berdasarkan kriteria Rekonsiliasi Data, Atribut, Absensi dan kinerja memerlukan ketelitian dan harus sesuai dengan skala kriteria. Selanjutnya perbandingan prosentase perhitungan sistem mampu memberikan rekomendasi kepada PT. Telkom Akses untuk menggunakan sistem tersebut karena sudah diuji dan berjalan dengan sangat baik dan memberikan hasil yang sesuai. Diharapkan ada pengembangan lebih lanjut terhadap penelitian ini karena sistem yang dibuat pada penelitian ini merupakan sistem yang baru pertama kali dibuat.. .

\section{Daftar Rujukan}

[1] Adianto, T. R., Arifin, Z., \& Khairina, D. M. (2017). Sistem Pendukung Keputusan Pemilihan Rumah Tinggal Di Perumahan Menggunakan Metode Simple Additive Weighting (SAW) (STUDI KASUS : KOTA SAMARINDA). Prosiding Seminar Ilmu Komputer dan Teknologi Informasi. Samarinda.

[2] Amalia, M. R., \& Utami, Y. D. (2018). Pemberian Reward Berdasarkan Penilaian Kinerja Karyawan Dengan Metode AHP Pada PT. Anugerah Protecindo. JURNAL ILMU PENGETAHUAN DAN TEKNOLOGI KOMPUTER, 181-188.

[3] Fitria, N. (2016, Januari 31). NAJMI FITRIA. Retrieved from najmif.blogspot.com: http://najmif.blogspot.com/2016/01/penghargaan-dan-hukumandalam-suatu.html

[4] Frieyadie. (2018). AHP Sebagai Penunjang Keputusan Untuk Penilaian Kinerja Kerja Karyawan SPBU. JURNAL TECHNO NUSA MANDIRI, 63-68.

[5] Irawan, Y., Sari, N., Rahmalisa, U., Wahyuni, R., \& Devis, Y. (2019). Aplikasi Pemberian Reward Berdasarkan Kinerja Karyawan Dengan Metode Analitycal Hierarchy Process (AHP) Pada Toko Golden Jaya Star Pekanbaru. JURNAL TEKNOLOGI DAN OPEN SOURCE, 87-101.

[6] Resti, C. N. (2017). Penerapan Metode Simple Additive Weighting (SAW) pada Sistem Pendukung Keputusan Pemilihan Lokasi untuk Cabang Baru Toko Pakan UD. Indo Multi Fish. JURNAL INTENSIF, 102-107.

[7] Susilowati, T., Sucipto, Nungsiyati, Kartika, A. T., \& Zaman, N. (2019). Penerapan Metode Simple Additive Weigting (SAW) Pada Amri Supermarket Banjar Jaya Untuk Pemilihan Karyawan Terbaik. JURNAL SISTEM INFORMASI DAN TELEMATIKA, 107-115.

[8] Turban, E. (2005). DECISION support systems and intelligent systems (sistem pendukung keputusan dan sistem cerdas). Yogyakarta: Andi Offset.

[9] Wulandari, S., \& Purnomo, A. S. (2019). Sistem Pendukung Keputusan Kenaikan Gaji Menggunakan Metode SAW (Studi Kasus: Cafe Sevenstones). Jurnal Multimedia \& Artificial Intelligence, Volume X, Nomor X

[10] Zulita,L. N. (2013). Sistem Pendukung Keputusan Menggunakan Metode SAW Untuk Penilaian Dosen Berprestasi (Studi Kasus di Universitas Dehasen Bengkulu).Jurnal Infotama 